\title{
Ghrelin and adipokines as circulating markers of disease activity in patients with Takayasu arteritis
}

\author{
Hatice Yilmaz', Vedat Gerdan², Didem Kozaci ${ }^{3}$, Dilek Solmaz², Servet Akar², Gercek Can², Aytac Gulcu4, \\ Yigit Goktay ${ }^{4}$, Ismail Sari ${ }^{2}$, Merih Birlik², Nurullah Akkoc ${ }^{2}$ and Fatos Onen ${ }^{2 *}$
}

\begin{abstract}
Introduction: The current markers of disease activity in Takayasu arteritis (TA) are insufficient for proper assessment. We investigated circulating levels of unacylated and acylated ghrelin, leptin and adiponectin and their relationships with disease activity in patients with TA.

Methods: This study included 31 patients with TA and 32 sex-, age- and body mass index-matched healthy controls. Disease activity was assessed in TA patients using various tools, including Kerr's criteria, disease extent index-Takayasu, physician's global assessment, radiological parameters, and laboratory markers. Plasma unacylated and acylated ghrelin, and serum leptin and adiponectin levels were measured using an enzyme-linked immunosorbent assay.

Results: Unacylated and acylated ghrelin levels were found to be significantly lower in TA patients than that in healthy controls. Patients with active disease had lower unacylated ghrelin levels than those with inactive disease and had lower acylated ghrelin levels than healthy controls. Ghrelin levels were negatively correlated with various parameters of disease activity. The leptin/ghrelin ratio was significantly higher in TA patients than controls. It was positively correlated with disease activity. There was a positive correlation between unacylated and acylated ghrelin and a negative correlation between leptin and ghrelin. There was no statistical difference in adiponectin levels between TA patients and controls. The radiological activity markers were positively correlated with other parameters of disease activity.
\end{abstract}

Conclusions: This study suggests that plasma unacylated and acylated ghrelin levels may be useful in monitoring disease activity and planning treatment strategies for patients with TA. The serum leptin level and leptin/ghrelin ratio may also be used to help assess the disease activity.

\section{Introduction}

Takayasu arteritis (TA) is a granulomatous panarteritis affecting large vessels, predominantly the aorta and its main branches. The disease is characterised by an acute phase with constitutional symptoms and followed by a vascular phase presented with symptoms due to stenosis, occlusion or aneurysms. However, these phases often overlap during the disease course [1].

The diagnosis of TA is based on its suggestive clinical features and imaging methods such as conventional angiography, magnetic resonance angiography (MRA) and ultrasonography (US). Conventional angiography is

\footnotetext{
* Correspondence: fatos.onen@deu.edu.tr

${ }^{2}$ Department of Internal Medicine, Division of Rheumatology, Dokuz Eylul

University School of Medicine, Inciralti/lzmir, 35340, Turkey

Full list of author information is available at the end of the article
}

the gold standard for diagnosis. It shows clear outlines of the lumen of affected arteries, whereas MRA and US can demonstrate thickening of the vascular wall of the aorta and its major branches [2-5].

Monitoring the disease activity is of great importance because intensive treatment is required in the active periods of TA. However, until now a reliable serological marker of disease activity has not been identified. Acute-phase reactants, such as erythrocyte sedimentation rate (ESR) and serum $\mathrm{C}$-reactive protein (CRP) may demonstrate active inflammation but their specificity and sensitivity are quite low [6]. ESR is increased in nearly half of the patients in clinical remission, while it is normal in $28 \%$ of the patients with active disease [7]. The current criteria for the assessment of disease activity in TA [7] are not sufficient either.

\section{C) Biomed Central}


Ghrelin, a recently discovered hormone, is produced primarily by cells in the stomach but is also expressed in white adipose tissue [8]. It has been shown to affect a number of different systems including growth hormone release, feeding, gastric acid secretion, gastric motility, and cell proliferation. Ghrelin and its receptor have been identified in $\mathrm{T}$ cells. It is a potent anti-inflammatory mediator in lymphocytes, monocytes and dendritic cells. It inhibits oxidative stress, cellular apoptosis, cell adhesion and proinflammatory cytokine expression and promotes IL-10 expression and cell migration [9].

Ghrelin is expressed in two different forms, namely acylated ghrelin and unacylated ghrelin. Initially, the unacylated ghrelin was considered to be biologically inactive but then a role of unacylated ghrelin in controlling the growth hormone $(\mathrm{GH})$-insulin-like growth factor 1 (IGF-I) axis has been demonstrated. Moreover, both acylated and unacylated forms of ghrelin have been shown to bind to common sites on cardiomyocytes and endothelial cells mediating similar signals to inhibit cellular apoptosis [10].

Adipokines, leptin and adiponectin are polypeptid hormones produced mainly by adipose tissue. Leptin regulates food intake and energy balance. It is now regarded as a pivotal factor in the interplay between neuroendocrine function and the immune system [11,12]. Proinflammatory cytokines increase circulating leptin, which in turn triggers cytokine release in monocytes/macrophages and stimulates $\mathrm{T}$ cell-mediated immunity during acute inflammation $[13,14]$. However, leptin may also limit the inflammatory response [15,16]. Adiponectin has antidiabetic and anti-atherogenic effects. It also appears to have anti-inflammatory properties because of its antagonism against TNF- $\alpha$ [17].

To our knowledge, there is no study investigating ghrelin and adipokines in TA, an inflammatory disease that is frequently accompanied by aneroxia and weight loss. In the current study, we aimed to investigate circulating unacylated and acylated ghrelin, leptin and adiponectin levels and to evaluate their relationships with disease activity in patients with TA.

\section{Materials and methods}

\section{Patients and controls}

Patients with TA followed up in the Division of Rheumatology, Dokuz Eylul University Medical Faculty (Izmir, Turkey) were called by telephone and invited to the hospital to participate in this study. We obtained detailed medical history and performed full physical examination on each patient who agreed to take part in this study. Thirty-two sex-, age- and body mass index (BMI)-matched hospital workers were evaluated as healthy controls.
The study was approved by the Dokuz Eylul University Ethics Committee for Non-invasive Clinical Research (project ethics number: B.30.2.DEU.0.01.00.00/ 15482). Written informed consent was obtained from all participants before enrollment.

\section{Assessment of disease activity}

Disease activity was assessed using various tools including Kerr's criteria [7], disease extent index-Takayasu (DEI.Tak) and physician's global assessment (PGA) [18], radiological parameters and acute-phase reactants.

Kerr's criteria [7] are used to define active disease if two of the following criteria are positive: 1) systemic features with no other cause; 2) elevated ESR; 3 ) features of vascular ischemia or inflammation (claudication, diminished or absent pulses, bruit, vascular pain, asymmetric blood pressure; or 4) typical angiographic features (in this study, MRA was also included to evaluate new vessel involvement or disease progression).

DEI.Tak [18] is a new index that was developed for follow up examinations of TA patients. DEI.Tak assesses clinical findings (without imaging) at intervals of at least 6 months, but only includes new or worsening symptoms that have developed within the past 6 months. TA patients with a DEI.Tak score $\geq 1.0$ at the time of this study were considered to have active disease. PGA is an item included on DEI.Tak, in which the physician classifies the disease status according to one of three categories: active disease, grumbling/persistent disease, or inactive disease.

Digital subtraction angiography (DSA) had been performed on all except one of the TA patients by the time of diagnosis. According to the TA follow up protocol of the Rheumatology and Radiology Board of our hospital, the TA patients are followed using three-monthly Bmode/ Doppler US and annual magnetic resonance imaging (MRI) with MRA examinations. Bilateral carotid, upper and lower extremity, renal and mesenteric arterial and abdominal aorta Doppler US examinations were performed to evaluate flow parameters and vessel wall thickness in all TA patients. MRI examinations, including examination of the aortic arch and supra-aortic arteries with specific investigations of the vessel walls and blackblood images were obtained before and after injection of a paramagnetic contrast agent to evaluate vessel wall enhancement. MRA examinations were performed to evaluate the whole aorta and its main branches.

We categorized the patients as having active disease based on the results of the radiological examinations if any of the following findings were positive: 1) new vessel involvement, as determined by any of the radiological studies including DSA, MRA and Doppler US; 2) increase in the carotid intima-media thickness (IMT) 
compared with a previous US examination; 3) the presence of vessel wall thickening and contrast enhancement on MRI.

All US and Doppler US examinations were performed by the same radiologist, as previously described [19], using an HDI-5000scanner (Advanced Technology Laboratories, Bothell, Washington, DC, USA) equipped with 12 to $5 \mathrm{MHz}$ and 7 to $5 \mathrm{MHz}$ linear array imaging probes. MR studies were performed by an Achieva $1.5 \mathrm{~T}$ MRI scanner (Philips Healthcare, Best, The Netherlands).

The serum C-reactive protein level (CRP, normal range 0.1 to $8.2 \mathrm{mg} / \mathrm{L}$ ), erythrocyte sedimentation rate (ESR, normal range 0 to $20 \mathrm{~mm} /$ hour), and total leukocyte and neutrophil numbers were measured as laboratory parameters of disease activity in TA patients and compared with those in the controls.

\section{Measurement of unacylated and acylated ghrelin, leptin, and adiponectin}

Overnight fasting-state blood samples (K2 ethylenediaminetetraacetic acid (EDTA)-treated and not) were obtained from patients and controls. Plasma leptin, adiponectin, unacylated ghrelin and acylated ghrelin levels were measured by ELISA kits, commercially available from Biovendor RDP (Brno, Czech Republic). The assays were performed according to the manufacturer's instructions. ELISA plates were coated with anti-human leptin, adiponectin, unacylated ghrelin and acylated ghrelin antibodies, respectively. Color was developed with 3,3',5,5'tetramethylbenzidine (TMB) and absorbance was measured at $450 \mathrm{~nm}$. Mean values were reported.

\section{Statistics}

The Kolmogorov-Smirnov test was used to determine if each parameter followed a normal distribution. The values are expressed as the mean $\pm \mathrm{SD}$, median, or percentage, as appropriate. For comparison of the groups, Kruskal-Wallis analysis or chi-square tests were used. When between-group significance was determined, data were compared in pairs using the Mann-Whitney $U$-test. Relationships were determined using the phi coefficient, Spearman's rho, or intraclass correlations. All statistical analyses were performed using SPSS software (version 15.0; SPSS Inc., Chicago, IL, USA). Differences were considered significant at $P<0.05$.

\section{Results}

\section{Demographic and clinical features}

In total, 31 patients ( 28 female and 3 male) who fulfilled the American College of Rheumatology (ACR) criteria for TA [20] were enrolled in this study. Their mean age was 44.2 years, and the median disease duration was 7 years (range 1 to 30 years). Thirty-two healthy sex-, age- and
BMI-matched hospital workers (28 female and 4 male, mean age 41.5 years) were evaluated as controls. The demographic, clinical and laboratory features of patients and controls are shown in Table 1.

According to the angiographic classification [21], eighteen patients with TA (58.1\%) had type 5 vessel involvement, ten had type 1 (32.3\%), two had type 4 (6.4\%) and one had type 2 (3.2\%). Coronary artery involvement was present in three of thirty-one TA patients. Nineteen TA patients $(68.7 \%)$ were using corticosteroid treatment during the study period. Immunosuppressive treatments included the following: methotrexate monotherapy in thirteen patients (41.9\%), methotrexate plus leflunomide in three patients $(9.7 \%)$, azathioprine monotherapy in ten patients (32.3\%), leflunomide monotherapy in three patients $(9.7 \%)$, and azathioprine plus leflunomide in one patient (3.2\%). One patient (3.2\%) was not receiving treatment.

Five patients $(16.1 \%)$ had undergone prior vascular surgery and twenty (64.5\%) had undergone percutaneous angioplasty.

\section{Disease activity in TA patients}

According to Kerr's criteria and the radiological definitions, six (20\%) and ten (33\%) TA patients respectively had active disease. Seventeen patients (53.1\%) had a DEI.Tak score $\geq 1.0$ at the time of the study; these patients were considered to have active disease. The mean DEI-Tak score was 1.0 at the time of the study. The increase in the mean DEI-Tak score value during the last six months was calculated as 0.17 . When the patients were evaluated according to the criteria of PGA, we found that six (19.4\%) patients had active disease, seven (22.6\%) had grumbling/persistent disease and eighteen (58.1\%) had inactive disease.

There was a significant positive correlation between radiological activity markers and Kerr's criteria, DEI-Tak and PGA $(r=0.408, P=0.023 ; r=0.463, P=0.009$; and $r=0.409, P=0.031$, respectively). Significant correlation was also determined between Kerr's criteria and DEI.Tak and Kerr's criteria and PGA $(r=0.566, P=$ 0.001 and $r=0.603, P=0.001$ respectively).

ESR and total leukocyte and neutrophil numbers were higher in TA patients than in controls (Table 1). We determined that the immunosuppressive treatment was changed in eight TA patients and the glucocorticoid dose was increased in three TA patients due to treatment failure during the last month. Both the change in immunosuppressive treatment and increase in glucocorticoid dose correlated well with Kerr's criteria $(r=$ $0.640, P<0.001$ and $r=0.667, P<0.001$, respectively), PGA $(r=0.570, P=0.002$ and $r=0.400, P=0.035$, respectively) and the radiological activity markers $(r=$ $0.370, P=0.042$ and $r=0.471, P=0.009$, respectively). 
Table 1 Characteristics of the patients with Takayasu arteritis and matched healthy controls

\begin{tabular}{|c|c|c|c|}
\hline & Takayasu patients $(n=31)$ & Healthy controls $(n=32)$ & $P$ \\
\hline Age, years, mean $\pm S D$ & $44.2 \pm 11.3$ & $41.5 \pm 5.9$ & 0.22 \\
\hline Sex, female/male, n & $28 / 3$ & $28 / 4$ & 1.00 \\
\hline Body mass index, mean \pm SD & $25.2 \pm 4.2$ & $25.0 \pm 3.3$ & 0.87 \\
\hline Waist circumference, $\mathrm{cm}$, mean \pm SD & $86.6 \pm 13.0$ & $83.4 \pm 10.0$ & 0.28 \\
\hline Hip circumference, $\mathrm{cm}$, mean \pm SD & $102.9 \pm 9.2$ & $104 \pm 7.5$ & 0.59 \\
\hline Diabetes mellitus, n (\%) & $3(9.7)$ & 0 & \\
\hline Hypertension, n (\%) & $12(38.7)$ & 0 & \\
\hline Hyperlipidemia, n (\%) & $9(29)$ & 0 & \\
\hline Coronary artery disease, n (\%) & $3(9.6)$ & 0 & \\
\hline Ever smoked, n (\%) & $4(12.9)$ & 0 & \\
\hline Menopausal, n (\%) & $11(39.3)$ & 0 & \\
\hline White blood cells, $\mathrm{n} / \mathrm{uL}$, mean $\pm \mathrm{SD}$ & $8622 \pm 3614$ & $6681 \pm 1237$ & 0.002 \\
\hline Neutrophil, n/uL, mean \pm SD & $5754 \pm 2747$ & $3878 \pm 1000$ & 0.001 \\
\hline Hemoglobin, $\mathrm{g} / \mathrm{dL}$, mean $\pm \mathrm{SD}$ & $12.5 \pm 1.7$ & $12.9 \pm 1.6$ & 0.21 \\
\hline $\mathrm{ESR}, \mathrm{mm} /$ hour, mean $\pm \mathrm{SD}$ & $28.3 \pm 24.1$ & $16.2 \pm 8.5$ & 0.017 \\
\hline C-reactive protein, $\mathrm{mg} / \mathrm{L}$, mean $\pm \mathrm{SD}$ & $11.7 \pm 24.6$ & $2.7 \pm 3.0$ & 0.11 \\
\hline
\end{tabular}

ESR, erythrocyte sedimentation rate

\section{Unacylated and acylated ghrelin levels}

Plasma unacylated and acylated ghrelin levels $(319.3 \pm$ $202.6 \mathrm{pg} / \mathrm{mL}$ and $120.5 \pm 94.4 \mathrm{pg} / \mathrm{mL}$, respectively) were found to be significantly lower in TA patients than healthy controls $(623.2 \pm 270.0 \mathrm{pg} / \mathrm{mL}$ and $180.9 \pm 128.7$ $\mathrm{pg} / \mathrm{mL}$, respectively) $(P<0.001$ and $P<0.05$, respectively $)$ (Table 2). Their levels were also lower in the patients with active disease than those with inactive disease according to PGA $(P<0.05$ for unacylated ghrelin (Figure 1) although the difference in acylated ghrelin levels did not reach statistical significance. Furthermore, the level of acylated ghrelin was lower in TA patients with active disease than in healthy controls according to both PGA $(P<0.05)$ (Figure 1$)$ and DEI-Tak $(P<0.05)$. There was no difference in acylated ghrelin levels between inactive patients and healthy controls (Figure 1).

The level of unacylated ghrelin was negatively correlated with DEI.Tak and PGA $(r=-0.428, \mathrm{p}=0.037$ and $\mathrm{r}$ $=-0.501, \mathrm{p}<0.001$ respectively). There was also a negative correlation between unacylated ghrelin and CRP, and the numbers of leukocyte and neutrophil $(\mathrm{r}=-0.269, \mathrm{p}=$ $0.033 ; \mathrm{r}=-0.373, \mathrm{p}=0.003$ and $\mathrm{r}=-0.395, \mathrm{p}=0.001$,

Table 2 The levels of unacylated and acylated ghrelin, leptin, and adiponectin in patients and controls

\begin{tabular}{llll}
\hline & TA & HC & $P$ \\
\hline Unacylated ghrelin, $\mathrm{pg} / \mathrm{mL}$ & $319.3 \pm 202.6$ & $623.2 \pm 270.0$ & $<0.001$ \\
Acylated ghrelin, $\mathrm{pg} / \mathrm{mL}$ & $120.5 \pm 94.4$ & $180.9 \pm 128.7$ & $<0.05$ \\
Leptin, $\mathrm{ng} / \mathrm{mL}$ & $72 \pm 62$ & $52 \pm 35$ & $\boldsymbol{\triangleright} 0.05$ \\
Adiponectin, $\mu \mathrm{g} / \mathrm{mL}$ & $16 \pm 9$ & $13 \pm 5$ & $\boldsymbol{>} 0.05$ \\
\hline
\end{tabular}

Results are presented as mean \pm SD. TA, Takayasu arteritis; HC, healthy controls. respectively) (Figure 2). The level of acylated ghrelin was also negatively correlated with CRP levels, and with leukocyte and neutrophil numbers $(r=-0.379, P=0.003, r=$ -0.332, $P=0.01$ and $r=-0.322, P=0.013$, respectively) (Figure 3).

The unacylated and acylated ghrelin levels were lower in patients who underwent changes in immunosuppressive medication than in patients who did not $(P=0.003$ and $P=0.018$, respectively). The unacylated and acylated ghrelin levels were also found to be lower in patients who underwent an increase in glucocorticoid dose than in patients who did not undergo an increase in glucocorticoid dose $(P=0.027$ and $P=0.020$, respectively). The levels of acylated and unacylated ghrelin in TA patients who had diabetes mellitus and hypertension were not statistically different from those who did not have these comorbidities $(P>0.05)$. Positive correlation was found between unacylated ghrelin and acylated ghrelin levels $(r=0.679, P<0.001)$ (Figure 4).

\section{Leptin and adiponectin levels}

Leptin level was higher in TA patients than in healthy controls but the difference did not reach statistical significance (Table 2). It was positively correlated with neutrophil numbers $(r=0.262, P=0.038)$. There was negative correlation between leptin and unacylated and acylated ghrelin levels $(r=-0.325, P=0.009$ and $r=-0.473, P<$ 0.001 , respectively) (Figure 5 ). The level of leptin was higher in patients who underwent an increase in glucocorticoid dose than those who did not $(P<0.05)$.

There was no statistical difference in adiponectin levels between TA patients and healthy controls (Table 2). The level of adiponectin was not different in the patients with 

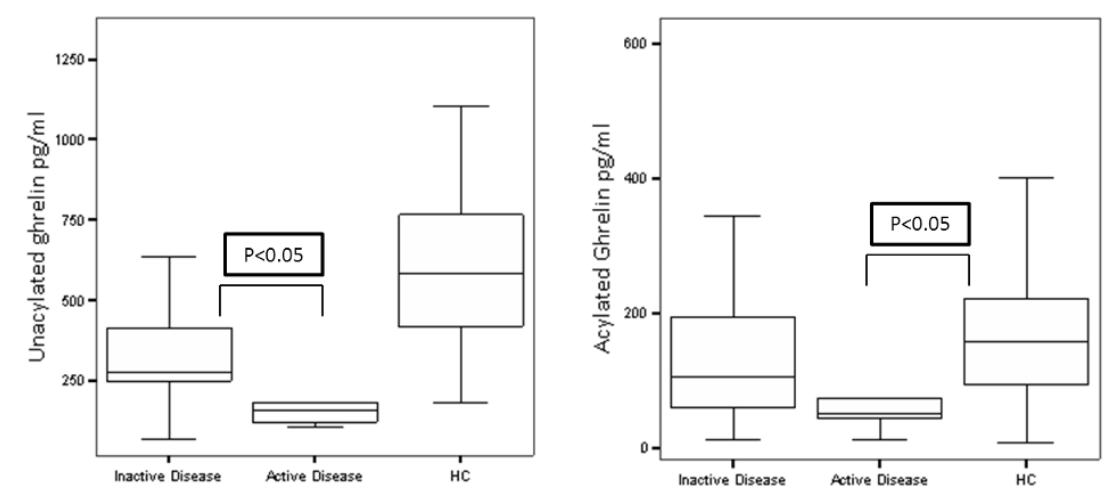

Figure 1 Plasma ghrelin levels in patients with Takayasu's arteritis (TA) and matched healthy controls. Patients with active disease had lower unacylated ghrelin levels than those with inactive disease (A) and had lower acylated ghrelin levels than healthy controls (B).

active disease compared with those with inactive disease and the controls.

\section{Leptin/ghrelin ratio}

The ratio of leptin/ghrelin was significantly higher in TA patients than in healthy controls $(P=0.001)$. It did not differ between TA patients with active or inactive disease. The ratio of leptin/ghrelin was correlated with Kerr's criteria, DEI.Tak, PGA, the radiological activity parameters and neutrophil numbers $(r=-0.367, P=$ $0.003 ; r=-0.370, P=0.003 ; r=-0.332, P=0.008 ; r=$ -0.377, $P=0.002 ; r=0.356, P=0.004$, respectively).

\section{The effect of glucocorticoid treatment on ghrelin and leptin levels}

No significant differences were found in unacylated and acylated ghrelin, and leptin levels between TA patients using glucocorticoid treatment and those not using glucocorticoid treatment $(P=0.162, P=0.530$ and $P=$ 0.400 , respectively).
The relationships of ghrelin and adipokines with BMI, and waist and hip circumference

Unacylated and acylated ghrelin, and adiponectin levels were negatively correlated with $\mathrm{BMI}(r=-0.302, P=0.016$; $r=-0.277, P=0.033$; and $r=-0.306, P<0.05$, respectively), waist circumference $(r=-0.423, P=0.001 ; r=$ -0.445, $P<0.001$ and $r=-0.285, P=<0.05$, respectively) and waist/hip ratio $(r=-0.416, P=0.001 ; r=-0.356, P=$ $0.006 ; r=-0.404, P=0.001$, respectively). A negative correlation between acylated ghrelin level and hip circumference $(r=-0.353, P=0.006)$ was also determined. The leptin level was positively correlated with BMI $(r=0.508$, $P<0.001)$, waist circumference $(r=0.435, P<0.001)$ and hip circumference $(r=0.546, P<0.001)$.

\section{The carotid artery ultrasound results}

The mean right and left carotid artery IMT measurements were $1.10 \pm 0.61 \mathrm{~mm}$ and $0.92 \pm 0.44 \mathrm{~mm}$, respectively. Among 31 patients with TA, 14 had diffuse and homogeneous IMT $>1 \mathrm{~mm}$ by B-mode US, which
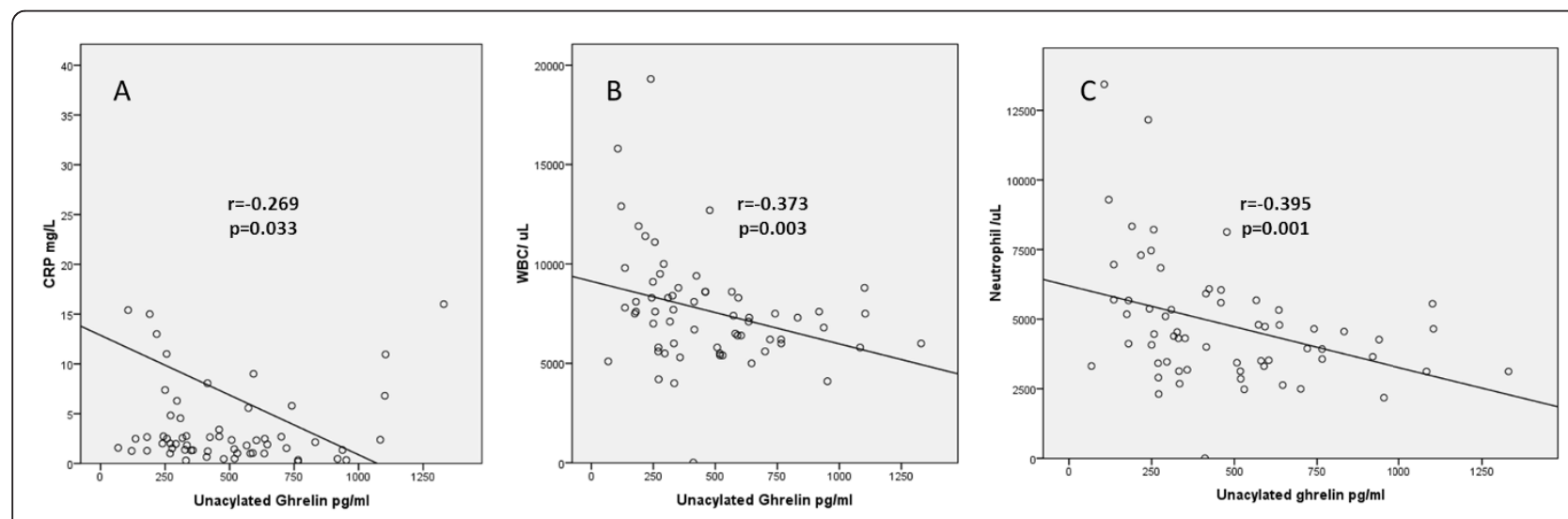

Figure 2 Negative correlations between plasma unacylated ghrelin levels and serum C-reactive protein (CRP) (A) and white blood cell count (WBC) numbers (B) and neutrophil numbers (C). 

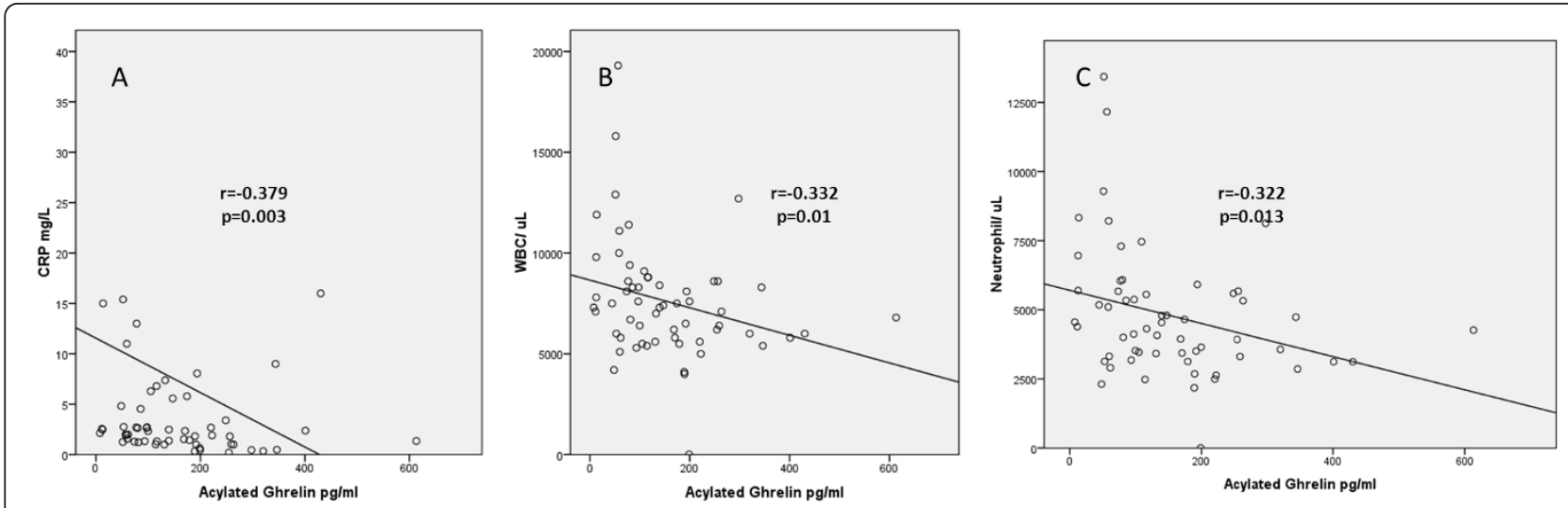

Figure 3 Negative correlations between plasma acylated ghrelin levels and serum C-reactive protein (CRP) (A) and white blood cell (WBC) numbers (B) and neutrophil numbers (C).

had been defined as suggestive for involvement with TA. Among these 14 patients, $10(71.4 \%)$ were already known to have carotid artery involvement identified by angiography or MRA. There was no relationship between mean carotid IMT and leptin, or ghrelin. The adiponectin level was positively correlated with the mean carotid IMT measurements $(r=0.522, P=0.004)$.

Four patients with TA (13.8\%) had carotid atherosclerotic plaques. Among them, two had coronary artery involvement. There was a significant relationship between the occurrence of carotid atherosclerotic plaque and coronary artery involvement $(P=0.004)$.

\section{Discussion}

Our study demonstrated decreased levels of circulating unacylated and acylated ghrelin in patients with TA. The ghrelin levels in patients with active disease were lower than those with inactive disease. Although the difference did not reach statistical significance, leptin levels in patients with active disease were increased. We also found that the leptin/ghrelin ratio was significantly higher in TA patients than in healthy controls. There was negative correlation between ghrelin levels and disease activity whereas the leptin/ghrelin ratio was positively correlated with disease activity. Furthermore, a reverse relationship was observed between leptin and ghrelin. The findings of decreased ghrelin and increased leptin in the patients who underwent treatment changes in the last month also supported the relationships of these hormones with active disease.

In the review of literature, we could find no study of the relationship of ghrelin and leptin with TA, and there was only one study investigating ghrelin levels in systemic vasculitis. In contrast to our results, this study showed that active anti-neutrophil cytoplasmic antibody (ANCA)-associated vasculitis is characterized by increased serum ghrelin and decreased serum leptin, both of which return to normal with successful therapy [22]. However, studies that have been performed in other forms of systemic vasculitis (including HenochSchönlein purpura and Behcet's disease) have shown increased levels of leptin in active disease periods [23-25]. Several studies have also reported increased leptin levels in systemic lupus erythematosus (SLE) [26-30] and rheumatoid arthritis (RA) patients [31-35], and some have demonstrated their correlation with disease activity [28,29,31-33,35]. There are a few reports on ghrelin that have revealed contradictory results in inflammatory rheumatic diseases. Increases in circulating ghrelin levels have been reported in ankylosing spondylitis (AS)[36] and RA. However, other studies have found significantly decreased ghrelin levels in patients with RA and in a rat adjuvant-induced arthritis model $[37,38]$. Decreased ghrelin levels have also been reported in patients with juvenile idiopathic arthritis. Furthermore, this last study has shown a significant relationship between ghrelin and disease activity [39].

All these studies confirmed the relationship of leptin and ghrelin with inflammation but it is unclear how the extent and severity of inflammation, the stage of disease progression, nutritional status and/or stress can impact this relationship. The other disease mechanisms may also directly or indirectly influence these hormones or the expression of their receptors in tissues. Thus, the discrepancies in the results of the studies may be explained by these factors as well as methodological differences.

Ghrelin has been shown to inhibit the leptin-induced cytokine expression in a dose-dependent manner, while leptin has upregulated ghrelin receptor-secretagogue receptor (GHS-R) expression on human T lymphocytes [9]. Leptin is known as a pure chemo-attractant and appears to have proangiogenic activity $[40,41]$ whereas ghrelin inhibits angiogenesis $[42,43]$. These findings 


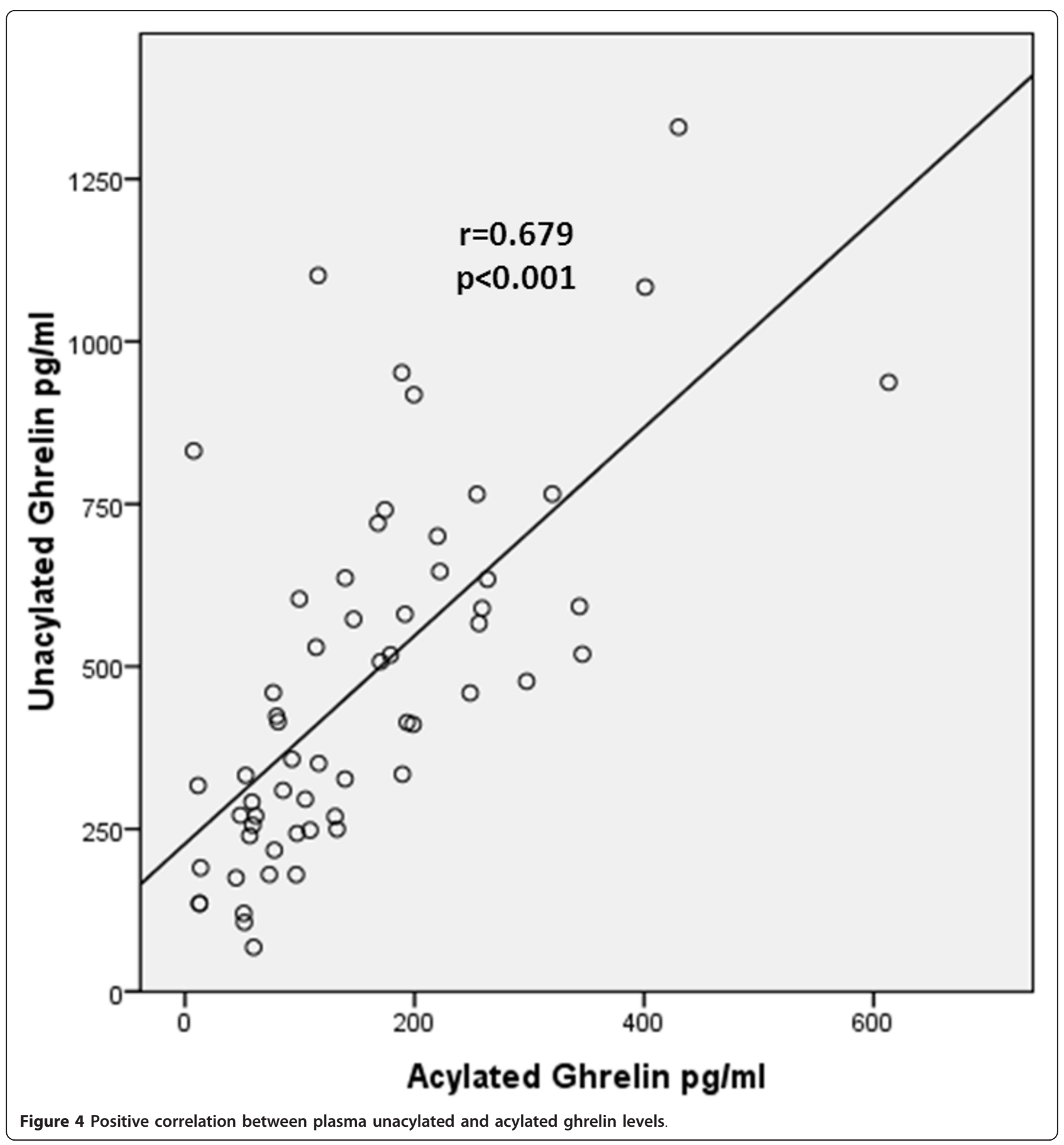

suggest the existence of a reciprocal regulatory network by which ghrelin and leptin control immune cell activation, inflammation and angiogenesis [9]. The present study also suggests a negative interaction between leptin and ghrelin.

In most of the studies, only total ghrelin levels were investigated and no attempts were made to differentiate between circulating acylated versus unacylated ghrelin levels [10]. In this study, we report a significant positive relation between the levels of these two forms of ghrelin in patients with TA and our results suggest that both of them are related to the inflammation.

Some studies have reported that low ghrelin levels are associated with type 2 diabetes, insulin resistance, and hypertension $[44,45]$. Therefore, we investigated the impact of comorbidities, including diabetes mellitus and hypertension, on the study results but we found no difference in acylated and unacylated ghrelin levels between 

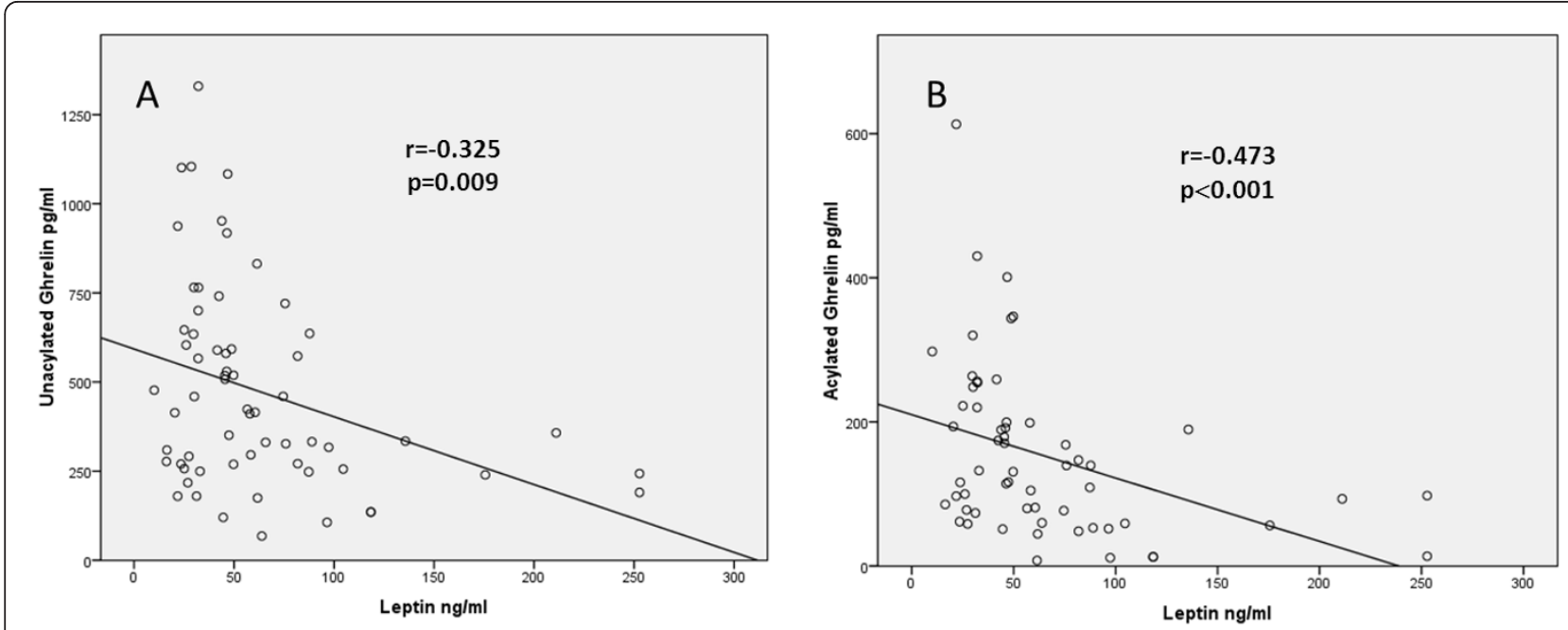

Figure 5 Negative correlations between serum leptin and plasma unacylated ghrelin (A) and acylated ghrelin levels (B).

TA patients who have these comorbidities and those who do not. Decreased ghrelin level under endogenously or exogenously induced hypercortisolism has been also reported previously [46], but we did not find any difference in unacylated and acylated ghrelin levels between patients using glucocorticoid treatment and those not using glucocorticoid treatment.

Although the level of adiponectin in patients with TA was not different from healthy controls, it was positively correlated with carotid IMT measurements, suggesting that there may be a relationship between adiponectin and disease activity. To our knowledge, there are no published data on adiponectin in TA or other systemic vasculitis.

Several studies have shown that BMI and waist/hip ratio positively correlate with leptin levels and negatively correlate with adiponectin and ghrelin levels in various disease groups and in healthy controls [47-51]. Therefore, we used a matching method to control for confounding effects due to anthropometric values. Meanwhile, our results were consistent with the previous studies that have shown these relationships.

The main limitation of our study is a lack of comparison of study variables between the pre-treatment and post-treatment periods in TA patients. However, there are several difficulties in performing a prospective study in TA, which is not a common disease [52,53]. There are problems in determining disease activity in patients with TA because a reliable marker is not yet available $[54,55]$ and many patients with TA have persistent disease associated with chronic low-grade inflammation. ESR and CRP are the most frequently used tools in the assessment of disease activity but their sensitivity and specificity are quite low [54,55]. Serum IL-6, and regulated and normal T cell-expressed and secreted (RANTES) levels have been shown to be increased in active disease periods and correlated with the disease activity score in patients with TA. However, a larger sample size and additional studies are required to confirm these results. Other studies that have investigated several markers of endothelial injury, platelet activity, and thrombotic and fibrinolytic status have failed to show a significant relationship between these markers and disease activity $[56,57]$. In contrast, plasma endothelin-1 levels have been demonstrated to be positively correlated with ESR in patients with TA [58]. A recent study reported that plasma levels of pentraxin-3 (PTX3), an acute phase reactant, which is produced by vascular and immune cells in response to proinflammatory signals, has greater accuracy for distinguishing active from inactive disease than either ESR or CRP [59], but it needs to be studied in a larger group of patients with unknown disease activity. The value of these tests in follow up is still uncertain.

We previously demonstrated that there is a very good agreement between Kerr's criteria and DEI.Tak, and using Kerr's criteria instead of DEI.Tak increases the consistency with PGA [60]. The latter finding has suggested that the physician's decision could be influenced by the acute-phase reactants and imaging modalities. In the present study, we showed that radiological markers of disease activity are consistent with Kerr's criteria, DEI-Tak and PGA. Therefore, we suggest that the radiological markers may help to evaluate disease activity in patients with TA.

\section{Conclusions}

This study demonstrated decreased levels of unacylated and acylated ghrelin in patients with TA. Patients with active disease had lower unacylated ghrelin levels than those with inactive disease and had lower acylated 
ghrelin levels than healthy controls. Ghrelin levels were negatively correlated with various parameters of disease activity. Furthermore, the leptin/ghrelin ratio was higher in TA patients than in controls. It was positively correlated with disease activity. There was a positive correlation between unacylated and acylated ghrelin and a negative correlation between leptin and ghrelin. No difference was determined in adiponectin levels between TA patients and controls.

The results of the study suggest that plasma unacylated and acylated ghrelin levels may be useful in monitoring disease activity and planning treatment strategies for patients with TA. The leptin/ghrelin ratio may also be used to help assess disease activity. Further studies are needed to validate the use of these laboratory tests in daily clinical practice.

\begin{abstract}
Abbreviations
ACR: American College of Rheumatology; ANCA: anti-neutrophil cytoplasmic antibody; AS: ankylosing spondylitis; BMI: body mass index; CRP: C- reactive protein; DEI.Tak: Disease Extent Index-Takayasu; DSA: digital subtraction angiography; ELISA: enzyme-linked immunosorbent assay; ESR: erythrocyte sedimentation rate; GH: growth hormone; GHS-R: ghrelin receptorsecretagogue receptor; IGF-1: insulin-like growth factor 1; IL: interleukin; IMT: intima-media thickness; MRA: magnetic resonance angiography; MRI: magnetic resonance imaging; PGA: physician's global assessment; PTX-3: pentraxin-3; RA: rheumatoid arthritis; RANTES: regulated and normal T cellexpressed and secreted; SLE: systemic lupus erythematosus; TA: Takayasu arteritis; TMB: 3,3',5,5'-tetramethylbenzidine;

TNF-a: tumor necrosis factor- alpha; US: ultrasonography; WBC: white blood cell.
\end{abstract}

\section{Authors' contributions}

$\mathrm{HY}$ and FO participated in the design of the study, acquisition, analysis and interpretation of data, and was involved in drafting the manuscript. VG participated in the design of the study, acquisition and interpretation of data. DK and DS participated in the design of the study, analysis and interpretation of data and was involved in drafting the manuscript. SA participated in the design of the study, acquisition, analysis and interpretation of data. GC, MB, and AG participated in the design of the study, and acquisition of data. YG participated in the design of the study and was involved in drafting the manuscript. IS participated in the design of the study, and interpretation of data. NA participated in the design of the study, and interpretation of data. All authors approved the final version of the manuscript for publication.

\section{Competing interests}

For all of authors there is no personal or financial relationship with other people or organizations that may influence the interpretation of data or presentation of information.

\section{Author details}

'Department of Internal Medicine, Dokuz Eylul University School of Medicine, Inciralti/lzmir, 35340, Turkey. ${ }^{2}$ Department of Internal Medicine, Division of Rheumatology, Dokuz Eylul University School of Medicine, Inciralti/lzmir, 35340, Turkey. ${ }^{3}$ Adnan Menderes University Science and Technology Research Center, Aydin, 09010, Turkey. ${ }^{4}$ Department of Radiodiagnostics, Dokuz Eylul University School of Medicine, Inciralti/lzmir, 35340, Turkey.

Received: 15 August 2012 Revised: 7 November 2012

Accepted: 11 December 2012 Published: 21 December 2012

\section{References}

1. Johnston SL, Lock RJ, Gompels MM: Takayasu arteritis: a review. J Clin Pathol 2002, 55:481-486.
2. Morrissey NJ, Goldman J, Fallon JT, Faries PL, Marin ML, Hollier LH: Endovascular aortic biopsy in the diagnosis of Takayasu arteritis. J Endovasc Ther 2003, 10:136-140.

3. Hata A, Numano F: Magnetic resonance imaging of vascular changes in Takayasu arteritis. Int J Cardiol 1995, 52:45-52.

4. Yamada I, Numano F, Suzuki S: Takayasu arteritis: evaluation with MR imaging. Radiology 1993, 188:89-94.

5. Kissin EY, Merkel PA: Diagnostic imaging in Takayasu arteritis. Curr Opin Rheumatol 2004, 16:31-37.

6. Kerr GS: Takayasu's arteritis. Rheum Dis Clin North Am 1995, 21:1041-1058.

7. Kerr GS, Hallahan CW, Giordano J, Leavitt RY, Fauci AS, Rottem M, Hoffman GS: Takayasu arteritis. Ann Intern Med 1994, 120:919-929.

8. Gnanapavan S, Kola B, Bustin SA, Morris DG, McGee P, Fairclough P, Bhattacharya S, Carpenter R, Grossman AB, Korbonits M: The tissue distribution of the mRNA of ghrelin and subtypes of its receptor, GHS-R, in humans. J Clin Endocrinol Metab 2002, 87:2988.

9. Dixit VD, Schaffer EM, Pyle RS, Collins GD, Sakthivel SK, Palaniappan R, Lillard JW Jr, Taub DD: Ghrelin inhibits leptin- and activation-induced proinflammatory cytokine expression by human monocytes and T cells. J Clin Invest 2004, 114:57-66.

10. Baatar D, Patel K, Taub DD: The effects of ghrelin on inflammation and the immune system. Mol Cell Endocrinol 2011, 340:44-58.

11. Zhang Y, Proenca R, Maffei M, Barone M, Leopold L, Friedman JM: Positional cloning of the mouse obese gene and its human homologue. Nature 1994, 372:425-432.

12. Brabant G, Nave H, Horn R, Anderwald C, Muller G, Roden M: In vivo and in vitro evidence for a hepatic modulation of the leptin signal in rats. Eur J Clin Invest 2004, 34:831-837.

13. Faggioni R, Feingold KR, Grunfeld C: Leptin regulation of the immune response and the immunodeficiency of malnutrition. FASEB J 2001, 15:2565-2571.

14. Lord GM, Matarese G, Howard JK, Baker RJ, Bloom SR, Lechler RI: Leptin modulates the T-cell immune response and reverses starvation-induced immunosuppression. Nature 1998, 394:897-901.

15. Palmer G, Gabay C: A role for leptin in rheumatic diseases? Ann Rheum Dis 2003, 62:913-915.

16. Bernotiene E, Palmer G, Gabay C: The role of leptin in innate and adaptive immune responses. Arthritis Res Ther 2006, 8:217.

17. Brochu-Gaudreau K, Rehfeldt C, Blouin R, Bordignon V, Murphy BD, Palin MF: Adiponectin action from head to toe. Endocrine 2010, 37:11-32.

18. Sivakumar M, Misra RN, Bacon PA: The Indian perspective of Takayasu arteritis and development of a disease extent index (DEl.Tak) to assess Takayasu arteritis. Rheumatology 2005, 44:iii6-7.

19. Manzi S, Selzer F, Sutton-Tyrrell K, Fitzgerald SG, Rairie JE, Tracy RP, Kuller LH: Prevalence and risk factors of carotid plaque in women with systemic lupus erythematosus. Arthritis Rheum 1999, 42:51-60.

20. Arend WP, Michel BA, Bloch DA, Hunder GG, Calabrese LH, Edworthy SM, Fauci AS, Leavitt RY, Lie JT, Lightfoot RW Jr, et al: The American College of Rheumatology 1990 criteria for the classification of Takayasu arteritis. Arthritis Rheum 1990, 33:1129-1134.

21. Numano F, Kobayashi Y: Takayasu arteritis-beyond pulselessness. Intern Med 1999, 38:226-232.

22. Kumpers $P$, Horn R, Brabant $G$, Woywodt A, Schiffer M, Haller H, Haubitz M: Serum leptin and ghrelin correlate with disease activity in ANCAassociated vasculitis. Rheumatology (Oxford) 2008, 47:484-487.

23. Aliyazicioglu Y, Ozkaya O, Yakut H, Islek I, Alvur M: Leptin levels in HenochSchonlein purpura. Clin Rheumatol 2007, 26:371-375.

24. Yalcindag FN, Kisa U, Batioglu F, Yalcindag A, Ozdemir O, Caglayan O: Serum leptin levels in patients with ocular and nonocular Behcet's disease. Mediators Inflamm 2007, 2007:31986.

25. Evereklioglu C, Inaloz HS, Kirtak N, Doganay S, Bulbul M, Ozerol E, Er H, Ozbek E: Serum leptin concentration is increased in patients with Behcet's syndrome and is correlated with disease activity. $\mathrm{Br}$ I Dermatol 2002, 147:331-336.

26. Garcia-Gonzalez A, Gonzalez-Lopez L, Valera-Gonzalez IC, CardonaMunoz EG, Salazar-Paramo M, Gonzalez-Ortiz M, Martinez-Abundis E, Gamez-Nava Jl: Serum leptin levels in women with systemic lupus erythematosus. Rheumatol Int 2002, 22:138-141.

27. Chung CP, Long AG, Solus JF, Rho YH, Oeser A, Raggi P, Stein CM: Adipocytokines in systemic lupus erythematosus: relationship to 
inflammation, insulin resistance and coronary atherosclerosis. Lupus 2009, 18:799-806.

28. Sada KE, Yamasaki Y, Maruyama M, Sugiyama H, Yamamura M, Maeshima $Y$, Makino $\mathrm{H}$ : Altered levels of adipocytokines in association with insulin resistance in patients with systemic lupus erythematosus. J Rheumatol 2006, 33:1545-1552.

29. Rovin BH, Song $H$, Hebert LA, Nadasdy T, Nadasdy G, Birmingham DJ, Yung Yu C, Nagaraja HN: Plasma, urine, and renal expression of adiponectin in human systemic lupus erythematosus. Kidney Int 2005, 68:1825-1833.

30. Al M, Ng L, Tyrrell P, Bargman J, Bradley T, Silverman E: Adipokines as novel biomarkers in paediatric systemic lupus erythematosus. Rheumatology (Oxford) 2009, 48:497-501.

31. Bokarewa M, Bokarew D, Hultgren O, Tarkowski A: Leptin consumption in the inflamed joints of patients with rheumatoid arthritis. Ann Rheum Dis 2003, 62:952-956.

32. Lee SW, Park MC, Park YB, Lee SK: Measurement of the serum leptin level could assist disease activity monitoring in rheumatoid arthritis. Rheumatol Int 2007, 27:537-540.

33. Targonska-Stepniak B, Majdan M, Dryglewska M: Leptin serum levels in rheumatoid arthritis patients: relation to disease duration and activity. Rheumatol Int 2008, 28:585-591.

34. Seven A, Guzel S, Aslan M, Hamuryudan V: Serum and synovial fluid leptin levels and markers of inflammation in rheumatoid arthritis. Rheumatol Int 2009, 29:743-747.

35. Otero M, Lago R, Gomez R, Lago F, Dieguez C, Gomez-Reino JJ, Gualillo O: Changes in plasma levels of fat-derived hormones adiponectin, leptin, resistin and visfatin in patients with rheumatoid arthritis. Ann Rheum Dis 2006, 65:1198-1201.

36. Toussirot E, Streit G, Nguyen NU, Dumoulin G, Le Huede G, Saas P, Wendling D: Adipose tissue, serum adipokines, and ghrelin in patients with ankylosing spondylitis. Metabolism 2007, 56:1383-1389.

37. Koca SS, Ozgen M, Aydin S, Dag S, Evren B, Isik A: Ghrelin and obestatin levels in rheumatoid arthritis. Inflammation 2008, 31:329-335.

38. Otero M, Nogueiras R, Lago F, Dieguez C, Gomez-Reino JJ, Gualillo O: Chronic inflammation modulates ghrelin levels in humans and rats. Rheumatology (Oxford) 2004, 43:306-310.

39. Karagiozoglou-Lampoudi T, Trachana M, Agakidis C, Pratsidou-Gertsi P, Taparkou A, Lampoudi S, Kanakoudi-Tsakalidou F: Ghrelin levels in patients with juvenile idiopathic arthritis: relation to anti-tumor necrosis factor treatment and disease activity. Metabolism 2011, 60:1359-1362.

40. Ottonello L, Gnerre P, Bertolotto M, Mancini M, Dapino P, Russo R, Garibotto G, Barreca T, Dallegri F: Leptin as a uremic toxin interferes with neutrophil chemotaxis. J Am Soc Nephrol 2004, 15:2366-2372.

41. Artwohl M, Roden M, Holzenbein T, Freudenthaler A, Waldhausl W, Baumgartner-Parzer SM: Modulation by leptin of proliferation and apoptosis in vascular endothelial cells. Int J Obes Relat Metab Disord 2002, 26:577-580.

42. Baiguera S, Conconi MT, Guidolin D, Mazzocchi G, Malendowicz LK, Parnigotto PP, Spinazzi R, Nussdorfer GG: Ghrelin inhibits in vitro angiogenic activity of rat brain microvascular endothelial cells. Int $\mathrm{J} \mathrm{Mol}$ Med 2004, 14:849-854.

43. Conconi MT, Nico B, Guidolin D, Baiguera S, Spinazzi R, Rebuffat P, Malendowicz LK, Vacca A, Carraro G, Parnigotto PP, Nussdorfer GG, Ribatti D: Ghrelin inhibits FGF-2-mediated angiogenesis in vitro and in vivo. Peptides 2004, 25:2179-2185.

44. Poykko SM, Kellokoski E, Horkko S, Kauma H, Kesaniemi YA, Ukkola O: Low plasma ghrelin is associated with insulin resistance, hypertension, and the prevalence of type 2 diabetes. Diabetes 2003, 52:2546-2553.

45. Li ZF, Guo ZF, Yang SG, Zheng X, Cao J, Qin YW: Circulating ghrelin and ghrelin to obestatin ratio are low in patients with untreated mild-tomoderate hypertension. Regul Pept 2010, 165:206-209.

46. Otto B, Tschop M, Heldwein W, Pfeiffer AF, Diederich S: Endogenous and exogenous glucocorticoids decrease plasma ghrelin in humans. Eur J Endocrinol 2004, 151:113-117.

47. Wang YH, Huang TS, Liang HW, Su TC, Chen SY, Wang TD: Fasting serum levels of adiponectin, ghrelin, and leptin in men with spinal cord injury. Arch Phys Med Rehabil 2005, 86:1964-1968.

48. Huang TS, Wang YH, Chen SY: The relation of serum leptin to body mass index and to serum cortisol in men with spinal cord injury. Arch Phys Med Rehabil 2000, 81:1582-1586.
49. Gomez JM, Maravall FJ, Gomez N, Navarro MA, Casamitjana R, Soler J: Interactions between serum leptin, the insulin-like growth factor-I system, and sex, age, anthropometric and body composition variables in a healthy population randomly selected. Clin Endocrinol (Oxf) 2003, 58:213-219.

50. Kozakowski J, Rabijewski M, Zgliczynski W: [Decrease in serum ghrelin levels in patients with acromegaly normalize after successful surgical treatment]. Endokrynol Pol 2005, 56:862-870.

51. Scerif M, Goldstone AP, Korbonits M: Ghrelin in obesity and endocrine diseases. Mol Cell Endocrinol 2011, 340:15-25.

52. Watts R, Al-Taiar A, Mooney J, Scott D, Macgregor A: The epidemiology of Takayasu arteritis in the UK. Rheumatology (Oxford) 2009, 48:1008-1011.

53. Kucukyavas Y, Aksu K, Solmaz D, Can G, Taylan A, Akar S, Sari I, Birlik M, Onen F, Akkoc N: Prevalence of Takayasu's Arteritis in Izmir, Turkey: A Multicenter Study. Annual European Congress of Rheumatology, EULAR 2012 Berlin, Germany; 2012, Abstract Book 61.

54. Salvarani C, Cantini F, Boiardi L, Hunder GG: Laboratory investigations useful in giant cell arteritis and Takayasu's arteritis. Clin Exp Rheumatol 2003, 21:S23-28.

55. Lagneau P, Michel JB, Vuong PN: Surgical treatment of Takayasu's disease. Ann Surg 1987, 205:157-166.

56. Hoffman GS, Ahmed AE: Surrogate markers of disease activity in patients with Takayasu arteritis. A preliminary report from The International Network for the Study of the Systemic Vasculitides (INSSYS). Int J Cardiol 1998, 66(Suppl 1):S191-194, discussion S195.

57. Akazawa H, Ikeda U, Yamamoto K, Kuroda T, Shimada K: Hypercoagulable state in patients with Takayasu's arteritis. Thromb Haemost 1996, 75:712-716.

58. Akazawa $H$, Ikeda U, Kuroda T, Shimada K: Plasma endothelin-1 levels in Takayasu's arteritis. Cardiology 1996, 87:303-305.

59. Dagna L, Salvo F, Tiraboschi M, Bozzolo EP, Franchini S, Doglioni C, Manfredi AA, Baldissera E, Sabbadini MG: Pentraxin-3 as a marker of disease activity in Takayasu arteritis. Ann Intern Med 2011, 155:425-433.

60. Aydin SZ, Yilmaz N, Akar S, Aksu K, Kamali S, Yucel E, Karadag O, Bicakcigil M, Ozer H, Kiraz S, Onen F, Inanc M, Keser G, Akkoc N, Direskeneli $\mathrm{H}$ : Assessment of disease activity and progression in Takayasu's arteritis with Disease Extent Index-Takayasu. Rheumatology (Oxford) 2010, 49:1889-1893.

doi:10.1186/ar4120

Cite this article as: Yilmaz et al:: Ghrelin and adipokines as circulating markers of disease activity in patients with Takayasu arteritis. Arthritis Research \& Therapy 2012 14:R272.

\section{Submit your next manuscript to BioMed Central and take full advantage of:}

- Convenient online submission

- Thorough peer review

- No space constraints or color figure charges

- Immediate publication on acceptance

- Inclusion in PubMed, CAS, Scopus and Google Scholar

- Research which is freely available for redistribution 